\title{
Aspectos éticos de la telemedicina ante la pandemia de Covid-19
}

\section{Ethical aspects of telemedicine in the face of Covid-19 pandemic}

\begin{abstract}
Jorge Alberto Álvarez Díaz*
https://doi.org/10.36105/mye.2021v32n1.07

\section{Resumen}

El artículo plantea condiciones clínico-epidemiológicas peculiares cuando la humanidad se enfrente a una zoonosis emergente. EI ejemplo que groseramente ha golpeado a la humanidad es la pandemia de Covid-19, enfermedad causada por el coronavirus SARS-CoV-2. Si bien la historia de la humanidad da cuenta de múltiples pandemias ocasionadas por varios agentes infectocontagiosos, es cierto que en el primer momento de afrontar una problemática global de esta naturaleza lo que prima es la incertidumbre. Ante ella, existe la obligación moral de proveer los mejores servicios de salud que sea posible; a la par, debe realizarse una investigación para encontrar medidas farmacéuticas específicas que contengan y mitiguen el daño poblacional (medicamentos específicos y/o vacunas). Mientras tanto, sabiendo que en el caso de la actual pandemia de Covid-19 la principal y más eficiente vía de transmisión es la propagación por gotas de saliva, el distanciamiento físico es crucial. Una consulta médica involucra
\end{abstract}

\footnotetext{
* Profesor del Departamento de Atención a la Salud de la División de Ciencias Biológicas y de la Salud, Universidad Autónoma Metropolitana, Unidad Xochimilco, Ciudad de México, México. Correo electrónico: bioética_reproductiva@hotmail .com http://orcid.org/0000-0001-9935-8632
}

Recepción: 20 de septiembre de 2020. Aceptación: 15 de octubre de 2020. 


\begin{abstract}
J. A. Álvarez Díaz
hablar en el interrogatorio y una proximidad física durante la exploración. Existen datos que indican que la telemedicina tiene un alto grado de recomendación para la protección de la salud, tanto de profesionales como de pacientes. Se recuerda que una declaración de la Asociación Médica Mundial ha tratado el tema de la telemedicina; con su exposición, se indican alcances, limitaciones y proyecciones en el futuro.
\end{abstract}

Palabras clave: SARS-CoV-2, telesalud, Asociación Médica Mundial.

\title{
1. La incertidumbre ante una zoonosis emergente
}

El avance que ha tenido la medicina junto con otras ciencias de la salud se ha dado en muy buena medida durante el siglo Xx. En el siglo XIX se originó en Francia un movimiento filosófico llamado positivismo, bajo la pluma de Auguste Comte. Una herencia de ese movimiento es la aplicación del método científico a las ciencias biomédicas. De modo muy general, durante la primera mitad del siglo $\mathrm{XX}$ se generan las aproximaciones metodológicas para realizar investigación en salud y, en la segunda mitad del mismo siglo, se va descubriendo que, además, deben incorporarse criterios éticos para la investigación. Con todo esto, no resulta fortuito el nacimiento de la bioética como un campo interdisciplinar a mediados de esa segunda mitad del siglo pasado.

Mucho más antiguo que esto - tan antiguo como la historia de la humanidad-, es hablar de pandemias. Las enfermedades infectocontagiosas que se dispersan por todo un país y alcanzan real o potencialmente al mundo aparecen en los textos hipocráticos, donde se encuentra el término «epidemia». Aparecen ya en la obra de Galeno (donde adquiere el sentido general más parecido al actual); se les puede encontrar lo mismo en textos bíblicos que en la literatura (El Decamerón, de Giovanni Bocaccio, se escribe tras una epidemia de peste; en el mismo siglo XX pueden encontrarse textos como 
La Peste, de Albert Camus, o El amor en los tiempos del cólera, de Gabriel García Márquez). Las epidemias que adquieren el grado de pandemia son fenómenos de toda la historia. No hay que olvidar que en 1520, en el siglo XVI, en lo que actualmente es México se tuvo una primera gran pandemia, la de bueyzábuatl (viruela). A mediados de ese mismo siglo se tuvo la de cocoliztli, que, de acuerdo con literatura reciente y basándose en técnicas de biología molecular, pudo haberse tratado de una salmonelosis (1). Hace un siglo, una pandemia de influenza pasó a la historia como la "gripe española»; diezmó de modo importante a la humanidad.

Además de llegar en un momento histórico en el que ya se cuenta con metodologías para hacer investigación en salud y con criterios éticos regulatorios (y cada vez más, también con criterios legales), la pandemia de Covid-19 tiene al menos un par de peculiaridades. Primera, el agente causal es un nuevo coronavirus entre los seres humanos, el SARS-CoV-2 (originalmente denominado como 2019-nCoV). Debido a las pandemias de influenza, se pensaba que la siguiente gran pandemia podría tratarse de este tipo de virus, y no de otro virus respiratorio, como el actual coronavirus. Segunda -que no se ha dicho con la fuerza y frecuencia debida-, ha llegado con resultados devastadores para la vida y la salud de la población de países desarrollados. SARS y MERS se desarrollaron fundamentalmente en el oriente; el Ébola, por el contrario, en África. $\mathrm{El}$ interés «mundial» radica en el interés de las naciones desarrolladas, al no tener medios para controlar este virus que está frenando sus pujantes economías (de ahí la abundante investigación, ensayos clínicos con fármacos, vacunas, publicaciones abiertas de las revistas arbitradas e indizadas, etcétera; como es bien sabido, este tipo de investigación es enormemente costosa).

Así las cosas, con la llegada de toda enfermedad emergente la investigación debe combinarse con la práctica clínica. Se debe tratar lo que se conoce, y lo que no, investigarse. En los meses en que el mundo ha sobrevivido con la pandemia, ya se saben muchas cosas y, como siempre, se desconocen muchas más. Desde su inicio 
se reconoció que el Covid-19 se trataba de la primera enfermedad profesional descrita en la década, y se pensaba que las experiencias con SARS y MERS serían de utilidad para enfrentar la nueva pandemia, sobre todo para identificar al personal de salud como personal de riesgo. Habría entonces que capacitarle en materia de protección y buenas prácticas de control de infecciones; además, ya se hacía énfasis en el apoyo adecuado en términos de salud psicosocial (2).

Las primeras investigaciones de corte cuantitativo mostraban que el $60 \%$ del personal de salud que resultaba infectado por el nuevo coronavirus era del grupo de enfermería, seguido por personal médico en un 30\%. Del personal médico, la mitad tenía cargos de mando medio (subdirectores), y una cuarta parte eran especialistas en medicina crítica y en neumología (3).

En ese primer trimestre de la pandemia se habían identificado tres etapas. En la primera, el Covid-19 se trataba de una enfermedad desconocida, teniendo al personal de salud mal protegido por puro desconocimiento. En la segunda, la enfermedad fue reconocida gradualmente. Una vez que se identificó la protección adecuada, parte del personal de salud continuaba protegido de forma incorrecta o incompleta, ya sea por falta de capacitación o debido a problemas en la producción, distribución y asignación de recursos especializados (los equipos de protección personal o EPP). En una tercera etapa se habría reconocido la gravedad de la enfermedad. Para entonces, el personal de salud ya debería estar totalmente protegido desde el punto de vista tecnocientífico, identificando los mejores equipos de acuerdo con la actividad profesional y, desde el punto de vista administrativo, no solamente con la compra y distribución adecuada, sino con lineamientos claros en las políticas y capacitación masiva (4).

A la hora de escribir este texto se continúa en esa tercera etapa. En el momento en que se establezcan medidas farmacéuticas seguras y eficaces (medicamentos y/o vacuna), se habrá pasado a una nueva etapa. Al inicio de esta larga etapa, cada país ha tenido que ser responsable de establecer formas adecuadas de proteger al per- 
sonal de salud. No se puede brindar atención de forma adecuada si no se cuenta con personal, o si está siendo gravemente diezmado. $\mathrm{Al}$ recordar que en el siglo XX se aprende a hacer investigación en salud y que ésta se regula poco a poco ética y legalmente, hay que referir una terminología importante: evidence based medicine. Se ha traducido como «medicina basada en evidencias», traducción que no es muy buena; sería mejor «medicina basada en pruebas». Las pruebas se van acumulando, a favor y en contra de prácticas diagnósticas y terapéuticas. Las investigaciones que tienen mayor fuerza para aportar pruebas son las que se desarrollan con metodología de ensayo clínico. Además de los diferentes «niveles de evidencia», se habla también de "grados de recomendación». Esta terminología es la adoptada para la elaboración de guías de práctica clínica, con el objetivo de brindar lo mejor de la investigación científica para conseguir el beneficio de un paciente particular (la idea de Sackett de lo que es y debe ser la evidence based medicine). Resulta relevante, porque hay medidas que no tienen evidencia suficiente (para seguir con la terminología más usual), pero también que hay datos que indican que tienen un grado de recomendación alto. Por ejemplo: llamar a una paciente por su nombre durante el trabajo de parto (dato presente en guías nacionales en México). No existe un ensayo clínico donde se compare un grupo en el cual se les llame por su nombre a las pacientes, con otro grupo donde se utilicen otros términos. Además de parecer sensato, hay razones fundamentadas desde la dignidad de la persona y reforzadas con perspectiva de género para recomendar esta práctica. En todo esto, ¿dónde queda la telemedicina?

\section{Grado de recomendación de la telemedicina en la pandemia de Covid-19}

Un serio problema de orden práctico es que, ante una zoonosis emergente, no hay mucho tiempo para pensar en ensayos clínicos. 
Generar un fármaco nuevo para una determinada condición, o una vacuna específica, puede llevar una década o más. En varias enfermedades no ha sido posible (por ejemplo, ante la pandemia de VIH de la década de 1980 no se ha conseguido desarrollar una vacuna, pero afortunadamente hay tratamientos que consiguen que, si se llevan adecuadamente, una persona puede tener una vida prácticamente normal, a tal grado que una persona positiva, pero con la carga viral indetectable por laboratorio, se le considera clínicamente como intransmisible). Los ensayos clínicos no son un diseño epidemiológico que se apliquen exclusivamente en las intervenciones farmacológicas; con variantes (así como con dificultades y especificaciones) deberían realizarse también para determinar el método de diagnóstico y los métodos terapéuticos (farmacológicos o no farmacológicos) en cualquier enfermedad o condición.

Siguiendo esta idea, si se ofrece una consulta presencial o una a distancia (apoyándose, por ejemplo, en métodos electrónicos), debería hacerse un ensayo para determinar si la presencialidad afecta o no al diagnóstico mismo o a algún otro factor. Si no hay ensayos, no se pueden hacer meta-análisis y, por lo tanto, no hay evidencia de la mejor calidad. Por lo dicho en la sección anterior, resulta que el grado de recomendación es muy alto, a pesar de la falta de evidencia. Por ello, la literatura especializada refiere ya que una parte de la respuesta de los sistemas de salud ante la epidemia de Covid19 debe incluir un sistema de telemedicina (5). Esa acción, llevada a cabo de forma inmediata, ayuda a la protección del personal de salud involucrado en la atención (6), fundamentalmente desde el triaje, para establecer si se requiere o no alguna intervención (sabiendo que la mayoría de los casos no requiere atención hospitalaria). Pensar en todas las posibilidades ha generado optimismo respecto de su uso por sus múltiples beneficios (7). Esto es así porque el apoyo con el uso de medios electrónicos, no solamente puede ayudar en el triaje inicial, sino que, analizando áreas de especialidad y recomendaciones por grupos de casos o diagnósticos, puede llevarse a cabo una consulta a distancia (8). 
Esto es una ampliación en la cultura de prevención que debe permanecer durante todo el periodo de la pandemia: debe protegerse a las personas potencialmente usuarias de los servicios de salud para que no se infecten por el SARS-CoV-2. La mejor forma de protegerlas es evitarles el riesgo de exposición al virus en un ambiente hospitalario: si no se desplazan, se mantiene el distanciamiento físico; de ese modo se previene y, con el apoyo en la telemedicina, se brinda el servicio en casos en que así sea posible. Uno de los primeros ejemplos reportados en la literatura de la actual pandemia es la teledermatología (9). Ésta es una especialidad en la que la inspección de las lesiones es esencial. Es cierto que en ocasiones la palpación de las mismas brinda información adicional, pero una buena historia clínica con inspección, incluso realizada a distancia, puede ser muy orientadora (al menos para determinar si se requiere alguna evaluación presencial).

Existen otras posibilidades que pueden pensarse, como los servicios de salud mental (10). Podría discutirse que, siendo la palabra el instrumento crucial para una sesión de psicoterapia, no habría demasiados problemas. Al poco tiempo de analizarlo, se cae en la cuenta de que la confianza para establecer una relación o alianza terapéutica puede ser más complicada precisamente por la distancia, dificultad que ya han encontrado en algunas investigaciones empíricas iniciales. Profesionales de la salud mental indican que, si bien hay algunas ventajas al no desplazarse, hay algunos otros desafíos éticos, como el manejo de la confidencialidad en los espacios tanto del profesional como de quien consulta (11). En este sentido debe valorarse si la intervención a distancia es por primera vez o con personas con quienes ya se han establecido sesiones previas.

Probablemente el campo que ha encontrado mayores argumentos a favor de una consulta a distancia es aquel que evita la llegada a una consulta presencial a personas con riesgo elevado de infectarse o de tener complicaciones. Esto incluye a personas adultas mayores o con enfermedades crónicas no transmisibles, entre las que destacan la hipertensión, obesidad, diabetes mellitus, enfermedades 
cardiovasculares, etcétera. Esto es complejo porque, a pesar de que alguna consulta no pueda brindarse de modo presencial, puede no ser posible acudir por los medicamentos, hacerse exámenes de laboratorio para el seguimiento de su control, etcétera, con una estrategia de telemedicina (12). Por ello, es importante pensar en términos generales y desarrollar políticas en salud, pero con el ideal de respetar la autonomía de las personas, para que evalúen responsablemente si acuden o no por una determinada situación de su padecimiento.

Si se piensa no sólo en términos de telemedicina, sino de un modo más amplio en telesalud, pueden realizarse estrategias de educación, prevención o promoción a través de medios electrónicos, evitando el desplazamiento de la población para recibir las intervenciones. También puede monitorizarse la respuesta social de la población ante la pandemia (13).

Como en toda estrategia, existen ventajas, desventajas y limitaciones. Suele pensarse que la población con algunas condiciones de vulnerabilidad, tales como el vivir en medios rurales alejados, estaría en desventaja. Deben pensarse con profundidad las condiciones que puedan dañar a la población históricamente más vulnerable al establecer políticas de salud; puede asignarse una persona, habitualmente personal de salud, para establecer la comunicación remota y transmitir así la información, dar seguimiento a pacientes, etcétera.

También es cierto que las nuevas tecnologías plantean algunos retos peculiares, como la posibilidad de rastreo de contactos que, si bien suena atractivo epidemiológicamente, no debe implementarse sin un adecuado análisis ético y jurídico, para no vulnerar la dignidad y confidencialidad de las personas ni violar sus derechos (14). Un reto, desde varios puntos de vista, es determinar qué se va a considerar como una asignación de servicios de atención médica «normal» o «estándar», después de todas las experiencias y la teoría generada a partir de las vivencias durante la pandemia (15). 


\section{Telemedicina en México: su aplicación en la pandemia de Covid-19}

La OMS ha definido la telemedicina como «aportar servicios de salud, donde la distancia es un factor crítico, por cualquier profesional de la salud, usando las nuevas tecnologías de la comunicación para el intercambio válido de información en el diagnóstico, el tratamiento y la prevención de enfermedades o lesiones; en la investigación y evaluación, además de en la educación continuada de los proveedores de salud, todo con el interés de mejorar la salud de los individuos y sus comunidades» (16). Por su parte, la OPS ha dicho que «la telesalud (incluyendo la telemedicina) involucra la entrega de servicios de salud usando las TICs, específicamente cuando la distancia es un obstáculo para los servicios de la salud» (17). Aunque hay literatura abundante y suficiente para distinguir entre «medicina» $\mathrm{y}$ «salud», se deja esta distinción amplia, en donde la telesalud incluye a la telemedicina.

La telemedicina puede realizarse de dos maneras en relación con el desarrollo de las actividades en el tiempo: de forma asincrónica y sincrónica. En el primer caso, se realiza una grabación, almacenamiento y transmisión de la información por parte de profesionales de la salud, que habitualmente son quienes están lejos de los centros de especialización o quienes requieren consultar a un especialista o a otro nivel de especialización; una vez que se recibe y analiza la información, se emite una respuesta. En el segundo caso, la emisión y recepción de la información se produce en tiempo real entre quien demanda los servicios y quien los proporciona, de modo que la recomendación y/o diagnóstico no difiere en el tiempo.

En el caso de la pandemia por Covid-19, la idea ha sido desarrollar telemedicina sincrónica, no necesariamente por distancia física, sino precisamente para evitar el contacto físico. Sabiendo que el mecanismo de contagio más eficiente son las gotas de saliva, lo que se ha buscado en los servicios de telemedicina es evitar ese componente. Por ello, ha existido un énfasis especial en el tamizaje de 
la población (para recomendar acudir o no a los servicios de salud, así como para las medidas a seguir en el domicilio), pero también para exámenes paraclínicos (como interconsultas en imagenología), apoyo en salud mental (para profesionales de la salud, pero también para información a familiares...), capacitación continua (como las actividades educativas de la Coordinación Nacional Médica del INSABI) (18), etcétera.

En México, la telemedicina se ha institucionalizado desde enero de 2004 tras la creación del Centro Nacional de Excelencia Tecnológica en Salud (CENETEC), nombrado en 2009 centro colaborador de la OMS. Tras estos eventos se han realizado reuniones y se ha producido literatura sobre este tema en la región de las Américas (19), analizando aspectos teóricos y experiencias prácticas en diferentes lugares del país (20). En 2017 se publicó una Cédula de Instrumentos Jurídicos aplicables a la práctica de la telesalud en México, que se actualizó en 2019 (21). En ella se entiende que aplican los mismos instrumentos que para la práctica médica presencial, variando solamente el procedimiento (sincrónico a distancia). Estos análisis vienen desde la publicación en el Diario Oficial de la Federación, el 21 de diciembre de 2015, del Proyecto de Norma Oficial Mexicana PROY-NOM-036-SSA3-2015, para la regulación de la atención médica a distancia. En el mismo Diario, el 27 de abril de 2018 se publicó el Aviso de Cancelación del Proyecto de Norma Oficial Mexicana PROY-NOM-036-SSA3-2015, para la regulación de la atención médica a distancia, publicado para consulta pública el 21 de diciembre de 2015.

Se ha encontrado que la telemedicina ofrece ventajas en México, fundamentalmente rompiendo la barrera de la distancia física, permitiendo una mayor cobertura, potencialmente un apego mayor a los tratamientos y una clara disminución de los costos de viaje, estancia y productividad (22). También se han encontrado sus limitaciones, derivadas de la fragmentación del Sistema Nacional de Salud, concentración de tecnologías en algunas regiones del país, costos altos de algunas TIC, además de por el desconocimiento de las mis- 
mas por parte del personal administrativo, de salud, así como de las personas que demandan atención (23).

Además de lo ya analizado sobre la telemedicina en México, la pandemia debe situarse en este contexto. Siendo un país de los catalogados como de bajo y mediano ingreso, deben realizarse consideraciones especiales de tipo socioeconómico (24). Existe abundante literatura para afirmar que la peor parte de la mayoría de las enfermedades agudas y crónicas recae en los pobres, y es muy probable que el mal estado socioeconómico afecte la propagación y los resultados de la epidemia de SARS-CoV-2 en México. Ciudades densamente pobladas (megalópolis), inseguridad alimentaria, acceso deficiente a servicios básicos como el agua, transporte público aglomerado, prevalencia alta de enfermedades crónicas no transmisibles, etcétera, son factores que promueven una alta transmisión del coronavirus. A esta serie de factores debe sumarse una infraestructura de los servicios de salud deteriorada por décadas de políticas neoliberales en salud, en las cuales también ha faltado la contratación de personal suficiente. Ante la escasez de camas de hospital, de instalaciones de cuidados intensivos y con personal de salud insuficiente, deben generarse condiciones para que se optimice el trabajo. Las políticas son decisivas para intentar resguardar en casa a la mayor parte de la población, tanto como sea posible (cuantitativamente y a lo largo del tiempo); para ayudar a que la población pueda saber si padece Covid-19 a fin de resguardarse en casa y no contagiar; para promover que acudan a los servicios de salud sólo quienes deben acudir, además de hacerlo de forma temprana y evitar así saturarlos tanto como sea posible. El reto ha sido y es inmenso.

A partir de toda esta compleja realidad se han derivado varias estrategias. Una de ellas es que resulta fundamental reconocer los casos sospechosos. El lineamiento epidemiológico generado desde febrero de 2020, y actualizado después en marzo y agosto de este mismo año, tiene claro que, para fines clínicos (no epidemiológicos), un caso sospechoso debe tratarse en casa como si fuese posi- 
tivo. En caso de complicaciones que sugieran severidad o gravedad, o en caso de tener comorbilidades que aumenten el riesgo de complicación y eventualmente la muerte, deben recibir evaluación médica y derivación oportuna al nivel adecuado de atención. Esto demanda muchos procesos complejos, comenzando por el tamizaje. El Gobierno de México ha creado una aplicación para telefonía móvil y su potencial uso a nivel nacional, Covid-19mx (disponible para descargarse de modo gratuito en las diferentes plataformas). Permite crear un perfil personal, hacer una prueba de tamizaje para sospechar diagnóstico y recibir información. Además, si se tiene activada la geolocalización, se identifican en un mapa las instituciones de salud y su capacidad para brindar atención según su grado de saturación en los servicios. El Gobierno de la Ciudad de México ha creado un servicio de mensajería de texto con un chatbot similar: enviando la palabra Covid19 al 51515, se tiene también una prueba de tamizaje. En caso de tener datos de alarma, existe la posibilidad de que personal de salud con entrenamiento en Covid-19 realice una videollamada para evaluar el estado del paciente, mediante una inspección dirigida a los datos de alarma. Dependiendo del resultado, se indica si quien solicita los servicios debe permanecer en casa (recibiendo apoyo alimentario, económico y monitoreo médico continuo), o si debe acudir a los servicios de salud para su seguimiento. Esta misma evaluación puede realizarse en una página web (25). También el Gobierno de la Ciudad de México cuenta con una aplicación, $A P P C d M \times$ 911, que brinda información sobre la capacidad hospitalaria. En el momento actual de la pandemia existe, además, un programa de atención especial a colonias prioritarias, aquéllas donde la tasa de incidencia es mayor.

Antes de pasar a la siguiente sección deben destacarse dos puntos: primero, hay que recordar que el sistema de salud en México, si bien se considera legalmente único, está fragmentado; por ello se han tenido que generar convenios para hacer eficiente la atención entre sectores privado y público, y dentro de éste, entre los subsis- 
temas IMSS, ISSSTE, PEMEX, SEDENA, SEMAR, etcétera. Segundo, el papel del Centro Regulador de Urgencias Médicas (CRUM) y la coordinación con los servicios de la línea 800 resultan esenciales para la canalización oportuna de los pacientes a los servicios que pueden recibirles y brindarles atención. Esto es absolutamente necesario para no responsabilizar exclusivamente a las personas sobre su atención, sino que representa una parte de la responsabilización de las instituciones del Estado respecto de la salud de la población.

\section{La bioética ante la telemedicina y la telesalud}

Como puede analizarse a esta altura de la reflexión, crear servicios de telemedicina tiene un componente ético en la base, que es prevenir el daño que potencialmente puede ocurrirles tanto a los profesionales de la salud como a las personas que demandan atención. Además de esta consideración inicial, debe quedar claro que toda aplicación de la tecnociencia conlleva retos específicos.

La Asociación Médica Mundial (AMM) se refiere con frecuencia, en temas de investigación, a los Principios éticos para las investigaciones médicas en seres bumanos, de la Declaración de Helsinki (1964). Sin embargo, siendo una organización de alcance mundial, cuenta con muchas otras declaraciones que abordan aspectos éticos de la práctica médica en entornos clínicos concretos, ante problemas delimitados, en situaciones definidas. Una de ellas trata precisamente de la telemedicina. Una primera versión, la Declaración de la Asociación Médica Mundial sobre las responsabilidades y normas éticas en la utilización de la telemedicina, fue adoptada por la 51 a Asamblea General de la Asociación Médica Mundial en Tel Aviv, Israel, en octubre de 1999. Posteriormente fue eliminada en la Asamblea General de la AMM en Pilanesberg, Sudáfrica, en octubre de 2006. Después se revisó y actualizó, de modo que la versión actual, la Declaración de la Asociación Médica Mundial sobre la ética de la telemedicina, fue adoptada por la $58^{\text {a }}$ Asamblea General de la AMM, en Copenhague, Dinamar- 
ca, en octubre 2007, y luego fue enmendada por la 69 Asamblea General de la AMM en Reikiavik, Islandia, en octubre de 2018 (26).

Como otros documentos de la Asociación Médica Mundial, la Declaración sobre la ética de la telemedicina tiene una estructura breve, concisa, pretendiendo su aplicabilidad. En su organización presenta los siguientes temas: definición, introducción (con cuatro puntos básicos); una serie de cuatro principios (respeto a normas éticas en cinco puntos; autonomía y privacidad del médico en cuatro puntos; responsabilidades del médico en siete puntos, y calidad de la atención en dos puntos), para finalizar con seis recomendaciones. Dada la relevancia del texto, se transcribe y se realizan algunos comentarios.

La definición utilizada como punto de partida es la siguiente: $L a$ telemedicina es el ejercicio de la medicina a distancia, cuyas intervenciones, diagnósticos, decisiones terapéuticas y recomendaciones de tratamientos subsiguientes están basadas en datos de los pacientes, documentos y otra información transmitida a través de sistemas de telecomunicación. La telemedicina puede realizarse entre un médico y un paciente o entre dos o más médicos, incluidos otros profesionales de la salud. La Declaración de Helsinki decía algo en su segundo punto que debe repensarse aquí: $A$ pesar de que la AMM está formada por profesionales de la medicina, las recomendaciones razonablemente alcanzan otras prácticas en la atención a la salud. En el caso del Covid-19 podría tratarse de personal de enfermería, inhaloterapia, terapia física, etcétera.

Los cuatro puntos de la introducción refieren algo similar al marco normativo mexicano: lo fundamental es la atención presencial, de modo que la telemedicina debe estar justificada y tener un marco ético y legal común con la práctica presencial. Estos puntos indican lo siguiente:

El desarrollo y la implementación de la tecnología de información y comunicación crean nuevas formas diferentes de ejercer la medicina y de prestar atención médica a los pacientes. La telemedicina se utiliza para los pacientes que no pueden ver un médico oportunamente por inacce- 
sibilidad debido a la distancia, discapacidad física, empleo, compromisos familiares (incluido el cuidado de otros); por el costo para el paciente y por los horarios de los médicos. Tiene la capacidad de llegar a algunos pacientes con acceso limitado a la asistencia médica y tiene potencial de mejorar la atención médica. De todos modos:

- La consulta presencial entre el médico y el paciente es la regla de oro de la atención clínica.

- Los servicios de la telemedicina deben ser consistentes con los servicios presenciales y respaldados con evidencia.

- Los principios de la ética médica que son obligatorios para la profesión también deben ser respetados en la práctica de la telemedicina.

La parte más densa de esta Declaración desde el punto de vista ético es, sin duda, la que lleva el título de «Principios» que, a su vez, va enumerando para establecer normas con cierta concreción. Retomando lo dicho en secciones previas de este texto, es posible ir construyendo una idea de una práctica ética de la telemedicina:

Cuando se practica la telemedicina, el médico debe respetar las siguientes normas éticas:

1. La relación médico-paciente debe estar basada en un examen personal y en un conocimiento suficiente del historial médico del paciente. La telemedicina debe ser utilizada principalmente en situaciones en las que el médico no puede estar presente físicamente en un tiempo seguro y aceptable. También se puede usar en la gestión de enfermedades crónicas o en el seguimiento después del tratamiento inicial, cuando se haya probado que es segura y eficaz.

2. La relación médico-paciente en la telemedicina debe estar basada en la confianza y respeto mutuos. Por lo tanto, es esencial que el médico y el paciente puedan identificarse con confianza cuando se utiliza la telemedicina. En el caso de consultas entre dos o más profesionales, en o entre jurisdicciones diferentes, el médico principal es responsable de la atención y de la coordinación del paciente con el equipo médico distante.

3. El médico debe tratar de garantizar que la confidencialidad del paciente, la privacidad y la integridad de los datos no se vean comprometidas. Los datos obtenidos durante una consulta de telemedicina deben asegurarse, para evitar el acceso no autorizado y las infracciones de la información identificable del paciente, a través de medidas 
de seguridad apropiadas y actualizadas de acuerdo con la legislación local. La transmisión electrónica de información también debe protegerse contra el acceso no autorizado.

4. El consentimiento informado adecuado requiere que toda la información necesaria sobre los distintos aspectos de las consultas por telemedicina sea explicada a fondo a los pacientes, incluida, pero no limitada a: explicar cómo funciona la telemedicina y cómo reservar citas; aspectos de privacidad; la posibilidad de fallas tecnológicas, incluidas violaciones de la confidencialidad; protocolos de contacto durante las consultas virtuales; políticas de prescripción y coordinación de la atención con otros profesionales de la salud, de manera clara y comprensible, sin influenciar la decisión del paciente.

5. Los médicos deben tener en cuenta que ciertas tecnologías de la telemedicina podrían ser inasequibles para los pacientes $y$, por esta causa, impedir su acceso. Un acceso desigual a la telemedicina puede ampliar aún más la brecha en salud entre ricos y pobres.

\section{Autonomía y privacidad del médico}

6. El médico no debe utilizar la telemedicina si infringe el marco legal o ético del país.

7. La telemedicina puede violar potencialmente la privacidad del médico, debido a la disponibilidad las 24 horas del día. El médico debe informar a los pacientes sobre la disponibilidad y recomendar servicios, como las urgencias, cuando no esté accesible.

8. El médico debe ejercer su autonomía profesional, al decidir si es apropiada una consulta por telemedicina frente a una presencial.

9. El médico debe ejercer su autonomía y discreción, al seleccionar la plataforma de telemedicina que utilizará.

\section{Responsabilidades del médico}

10. El médico al que se le pide su opinión a través de la telemedicina debe mantener un registro detallado de los consejos que entrega, como también de la información recibida, en la cual basó su consejo para asegurar la trazabilidad.

11. Si se toma la decisión de usar la telemedicina, es necesario asegurarse de que los usuarios (el paciente y los profesionales de la salud) puedan utilizar el sistema de telecomunicación necesario.

12. El médico debe tratar de asegurarse de que el paciente haya comprendido el consejo y las sugerencias de tratamiento entregadas, y en lo posible tome medidas para promover la continuidad de la atención. 
13. El médico que pide a otro médico consejo o una segunda opinión es responsable del tratamiento y de otras decisiones y recomendaciones dadas al paciente.

14. El médico debe estar consciente y respetar las dificultades e incertidumbres que puedan presentarse cuando esté en contacto con el paciente a través de la telecomunicación. El médico debe estar preparado para recomendar un contacto directo médico-paciente cuando estime que es en beneficio del paciente.

15. El médico sólo debe utilizar la telemedicina en países/jurisdicciones donde tenga licencia para emplearla. Las consultas de jurisdicciones cruzadas sólo deben permitirse entre dos médicos.

16. El médico debe asegurarse que su seguro médico incluye la telemedicina.

\section{Calidad de la atención}

17. Se deben utilizar regularmente medidas de evaluación de la calidad de la atención, para asegurar la seguridad del paciente y el mejor diagnóstico y prácticas de tratamiento posibles en la telemedicina. La prestación de servicios de telemedicina debe seguir las normas de práctica con base en la evidencia hasta donde estén disponibles, para asegurar la seguridad del paciente, la calidad de la atención y los resultados de salud positivos. Al igual que todas las intervenciones de salud, se debe probar la eficacia, seguridad, viabilidad y rentabilidad de la telemedicina.

18. Las posibilidades y debilidades de la telemedicina en emergencias deben ser identificadas debidamente. Si es necesario utilizar la telemedicina durante una emergencia, los consejos y sugerencias de tratamientos son influenciados por la gravedad de la condición del paciente y la competencia de las personas que están con el paciente. Las entidades que prestan servicios de telemedicina deben establecer protocolos para los casos de emergencias.

Toda declaración de normas o principios éticos lo que busca finalmente es la acción. Toda ética establece, de diferentes formas (y fundamentaciones), mundos que son ideales, que no existen, pero que señalan que la obligación ética de los seres humanos es intentar realizarlos del modo más completo posible en el menor tiempo posible. Tal vez se vaya la vida en ello, pero es la forma de actuar 
con ética. Así, la Declaración de la AMM de 2018 sobre la ética de la telemedicina termina con una serie de recomendaciones que invitan a la acción:

1. La telemedicina se debe adaptar apropiadamente a los marcos reguladores locales, que pueden incluir la licencia de plataformas de telemedicina para beneficio del paciente.

2. Cuando sea apropiado, la AMM y las asociaciones médicas nacionales deben promover la creación de normas éticas sobre esta práctica; de legislación nacional y acuerdos internacionales sobre asuntos relacionados con el uso de la telemedicina, mientras se protege la relación médico-paciente, la confidencialidad y la calidad de la atención médica.

3. La telemedicina no debe considerarse igual a una atención médica presencial, y no debe utilizarse sólo para reducir costos o como un incentivo perverso para servicios excesivos y aumentar las ganancias para los médicos.

4. El uso de la telemedicina requiere que la profesión identifique explícitamente y gestione las consecuencias adversas en las relaciones de compañerismo y patrones de referencia.

5. Las nuevas tecnologías y estilos con la integración de esta práctica pueden necesitar nuevas normas y estándares.

6. Los médicos deben presionar por una telemedicina ética en beneficio del paciente.

\section{Palabras finales}

Varios puntos resultan llamativos. Por un lado, que la Declaración de la AMM no ha tenido gran difusión en la literatura especializada. Por ejemplo, en la conocida base de datos PubMed no llega a una docena de trabajos donde se la cite. Uno de ellos, bien documentado y crítico, plantea escenarios con oportunidades de atención clínica en telemedicina, problemas éticos que se generan y formas de aproximación tomando en cuenta la Declaración (27). También llama la atención que en muchos lugares se han tenido muy diversas iniciativas de telemedicina ante la pandemia de Covid-19, desde es- 
trategias que buscan integralidad, hasta otras más puntuales; con todo, no hay artículos especializados que hablen sobre la Declaración, aunque sí hay bastantes que realizan análisis o comentarios de tipo ético. En el momento de elaborar este texto pueden encontrarse en la misma base de datos de PubMed, 1,604 citas que incluyen Covid-19 y Ethics, en tanto que si se combina Covid-19 con Bioethics aparecen 280 resultados. Ninguno menciona la Declaración. No se trata de basar todo análisis en la Declaración de la AMM, pero hay que reconocer que es un insumo que puede aportar elementos para la construcción de una ética de la telemedicina en situaciones de desastre en general, y de pandemias en particular. Además, toda ética busca guiar u orientar el acto concreto, y no limitarse meramente a la reflexión; de este modo, deben existir análisis particulares para cada pandemia (no es lo mismo hablar de Ébola, influenza o coronavirus). Habrá que analizar el resto del curso de la pandemia actual para determinar cuáles prácticas fueron las mejores, si se genera evidencia de alguna manera o si es mera experiencia, y cómo poder integrar toda esa información en la construcción de una bioética dirigida a una pandemia, como la que ha hecho replantear tantos aspectos a la humanidad en su conjunto.

Finalmente, debe quedar claro que una Declaración en temas de ética siempre es orientadora, pero no limitativa. Esto es, ofrece guías razonables para la acción ética que nunca podrán agotar los problemas derivados del tema tratado en la Declaración. El ejemplo más crudo para el futuro próximo ante la actual pandemia de Covid-19 es el tema de las aplicaciones para el rastreo de contagios. Sería deseable que en alguna reunión de la Asociación Médica Mundial se analizara el tema y se tomara una postura, no con la pretensión de resolver la problemática, sino para establecer líneas para la deliberación. La espera continúa. 


\section{Referencias bibliográficas}

1. Vagene AJ, Herbig A, Campana MG, Robles García NM, Warinner C, Sabin S, Spyrou MA, Andrades Valtueña A, Huson D, Tuross N, Bos KI, Krause J. Salmonella enterica genomes from victims of a major sixteenth-century epidemic in Mexico. Nat Ecol Evol. 2018; 2(3): 520-528. https://doi.org/10.1038/s41559-017-0446-6.

2. Koh D. Occupational risks for Covid-19 infection. Occup Med (Lond). 2020; 70(1): 3-5. https://doi.org/10.1093/occmed/kqaa036.

3. Wang J, Zhou M, Liu F. Reasons for healthcare workers becoming infected with novel coronavirus disease 2019 (Covid-19) in China. J Hosp Infect. 2020; 105(1): 100-101. https://doi.org/10.1016/j.jhin.2020.03.002.

4. Chen W, Huang Y. To protect healthcare workers better, to save more lives. Anesth Analg. 2020; 131(1): 97-101. https://doi.org/10.1213/ANE.000000000000 4834 .

5. Rockwell KL, Gilroy AS. Incorporating telemedicine as part of Covid-19 outbreak response systems. Am J Manag Care. 2020; 26(4): 147-148. https://doi.org/ 10.37765/ajmc.2020.42784.

6. Moazzami B, Razavi-Khorasani N, Dooghaie Moghadam A, Farokhi E, Rezaei N. Covid-19 and telemedicine: Immediate action required for maintaining healthcare providers well-being. J Clin Virol. 2020; 126: 104345. https://doi.org/10.1016/ j.jcv.2020.104345.

7. Hollander JE, Carr BG. Virtually perfect? Telemedicine for Covid-19. N Engl J Med. 2020; 382(18): 1679-1681. https://doi.org/10.1056/NEJMp2003539.

8. Greenhalgh T, Wherton J, Shaw S, Morrison C. Video consultations for Covid19. BMJ. 2020 Mar 12; 368: m998. https://doi.org/10.1136/bmj.m998.

9. Rismiller K, Cartron AM, Trinidad JCL. Inpatient teledermatology during the Covid-19 pandemic. J Dermatolog Treat. 2020; 31(5): 441-443. https://doi.org/10. 1080/09546634.2020.1762843.

10. Sousa A, Karia S. Telepsychiatry during Covid-19: Some clinical, public health, and ethical dilemmas. Indian J Public Health. 2020; 64(Supplement): S245-S246. https://doi.org/10.4103/ijph.IJPH_511_20.

11. Olwill C, Mc Nally D, Douglas L. Psychiatrist experience of remote consultations by telephone in an outpatient psychiatric department during the Covid-19 pandemic. Ir J Psychol Med. 2020 May 22; 1-8. https://doi.org/10.1017/ipm.2020.51

12. Basu S. Non-communicable disease management in vulnerable patients during Covid-19. Indian J Med Ethics. 2020; V(2): 103-105. https://doi.org/10.20529/ IJME.2020.041.

13. Fagherazzi G, Goetzinger C, Rashid MA, Aguayo GA, Huiart L. Digital health strategies to fight Covid-19 worldwide: Challenges, recommendations, and a call for papers. J Med Internet Res. 2020 Jun 16; 22(6): e19284. https://doi.org/10.2196/ 19284.

14. Vokinger KN, Nittas V, Witt CM, Fabrikant SI, von Wyl V. Digital health and the Covid-19 epidemic: An assessment framework for apps from an epidemiological 
and legal perspective. Swiss Med Wkly. 2020 May 17; 150: w20282. https://doi.org/ 10.4414/smw.2020.20282.

15. Garrett JR, McNolty LA, Wolfe ID, Lantos JD. Our next pandemic ethics challenge? Allocating «normal» health care services. Hastings Cent Rep. 2020; 50(3): 79-80. https://doi.org/10.1002/hast.1145. PMID: 32596905.

16. WHO (World Health Organization). Telemedicine. Opportunities and developments in member states. Report on the second global survey on eHealth. Global Observatory for eHealth series. Volume 2. [Consultado el 10 de octubre de 2020]. Recuperado en: http://www.who.int/goe/publications/goe_telemedicine_2010.pdf https://doi.org/10.4258/hir.2012.18.2.153

17. OPS (Organización Panamericana de la Salud). Telesalud. [Consultado el 10 de octubre de 2020]. Recuperado en: https://www.paho.org/ict4health/index.php? option=com_content\&view=article\&id=9684:telehealth\&ltemid=193\&lang=es

18. Coordinación Nacional Médica del INSABI. Entrenamiento continuo sobre manejo clínico para profesionales de la salud. [Consultado el 10 de octubre de 2020]. Recuperado en: https://coviduti.salud.gob.mx/registro/ https://doi.org/ 10.29193/rmu.36.2.2

19. Dos Santos AF, Fernández A, (Eds.). Desarrollo de la telesalud en América Latina. Aspectos conceptuales y estado actual. Santiago de Chile: Comisión Económica para América Latina y el Caribe (CEPAL); 2013. [Consultado el 10 de octubre de 2020]. Recuperado en: http://www.saludzac.gob.mx/home/docs/Telesalud/ TelesaludMexico/Desarrollo.pdf https://doi.org/10.20983/reij.2018.2.6

20. González Rétiz ML, Pacheco López A. Desarrollo de la telesalud en México. Santiago de Chile: Comisión Económica para América Latina y el Caribe (CEPAL); 2013. [Consultado el 10 de octubre de 2020]. Recuperado en: https:// repositorio.ce pal.org/bitstream/handle/11362/4055/1/S2012935_es.pdf https:// doi.org/10.20983/reij.2018.2.6

21. Secretaría de Salud, CENETEC-Salud. Cédula de Instrumentos Jurídicos aplicables a la práctica de la telesalud en México. $2^{a}$ ed. México: Secretaría de Salud, Centro Nacional de Excelencia Tecnológica en Salud; 2019. [Consultado el 10 de octubre de 2020]. Recuperado en: https://www.gob.mx/cms/uploads/attachment/ file/534418/CedulalnstrumentosJuridicosTelesalud_feb2020.pdf https://doi.org/ 10.1590/s0036-36342000000300012

22. Dabaghi Richerand A, Chávarri A, Torres Gómez A. Telemedicina en México. An Med (Mex). 2012; 57(4): 353-357.

23. Mariscal Avilés J, Gil García JR, Ramírez Hernández F. e-Salud en México: antecedentes, objetivos, logros y retos. Espacios Públicos. 2012; 15(34): 65-94.

24. Hodkinson B, Singh P, Gcelu A, Molano WB, Pons Estel G, Alpízar Rodríguez D. Navigating Covid-19 in the developing world. Clin Rheumatol. 2020; 39(7): 2039-2042. https://doi.org/10.1007/s10067-020-05159-4.

25. El gobierno de la CdMx se preocupa por tu salud. [Consultado el 10 de octubre de 2020]. Recuperado en: https://test.covid19.cdmx.gob.mx 


\section{J. A. Álvarez Díaz}

26. Declaración de la Asociación Médica Mundial sobre la ética de la telemedicina. [Consultado el 10 de octubre de 2020]. Recuperado en: https://www.wma.net/ es/policies-post/declaracion-de-la-amm-sobre-la-etica-de-la-telemedicina/ https:// doi.org/10.3989/isegoria.1994.i10.269

27. Humbyrd CJ. Virtue ethics in a value-driven world: Ethical telemedicine. Clin

Orthop Relat Res. 2019; 477(12): 2639-2641. https://doi.org/10.1097/CORR.0000 000000000908. 